\title{
La reelección presidencial indefinida en Venezuela, Nicaragua, Ecuador y Bolivia
}

The evasion of presidential term limits in Venezuela, Nicaragua, Ecuador and Bolivia

\author{
Agustín GriJALVA Jiménez \\ Universidad Andina Simón Bolívar \\ agustin@uasb.edu.ec \\ José Luis CAstro-Montero \\ Universidad Andina Simón Bolívar \\ j.I.castromontero1@gmail.com
}

Resumen: Durante la última década, los gobiernos de Venezuela, Nicaragua, Ecuador y Bolivia activaron procesos de reforma constitucional orientados a instituir la reelección presidencial indefinida, permitiendo que una misma persona postule a la presidencia sin restricciones. Este artículo analiza cuáles fueron las condiciones institucionales que en las cuales se adoptó esta fórmula de reelección. A partir del análisis comparativo, concluimos que la introducción de la reelección presidencial indefinida es el resultado de una crisis institucional muy marcada por el híper presidencialismo, el deterioro de la independencia judicial y la flexibilidad de los procedimientos de cambio constitucional. El hecho de que los países que adoptaron la reelección indefinida actualmente sean caracterizados como semi democracias o autoritarismos no es un de ninguna manera un dato circunstancial. La adopción de la reelección indefinida, de hecho, ha 
constituido un claro atajo en el camino autoritario y des-democratizador que estos países han transitado durante la última década.

Palabras clave: presidencialismo, reelección, América Latina, democracia, reforma constitucional

\begin{abstract}
During the last decade, the Venezuelan, Nicaraguan, Ecuadorian and Bolivian governments pushed through several constitutional amendments attempting to remove presidential term limits. In this article, we reflect on how institutional settings helped or prevented presidents in eliminating constitutional term limits. We find that factors as hyper-presidentialism, lack of judicial independence and flexible rules for amending constitutions were instrumental for allowing the president to circumvent constitutional limitations and remain in office. The evasion of constitutional term limits can thus be seen as a way of collapsing democratic regimes.
\end{abstract}

Keywords: Presidential system, term limits, Latin America, democracy, constitutional amendment.

\title{
1. Introducción
}

Desde los inicios de los regímenes presidenciales modernos, la reelección del presidente ocupó un lugar prominente en el debate político. Este debate originalmente enfrentó dos posiciones antagónicas. Por una parte, quienes defendieron la reelección presidencial, la destacaron como un mecanismo que garantiza la continuidad de las políticas de Estado, respeta la voluntad democrática y además constituye un incentivo para que un gobierno con experiencia actúe de forma responsable, honesta y eficiente, de forma que los ciudadanos lo sigan apoyando en las urnas. Por otra parte, los críticos de la reelección presidencial no dejaron de señalar sus riesgos, como la personalización y concentración del poder, agravada por el hecho de que una misma persona y su entorno lo detenten por largo tiempo. Esta continuidad, según estas voces, podría traducirse en la supresión del principio de alternancia democrática y el debilitamiento de la competencia electoral.

Durante el siglo XIX e inicios del siglo XX, en algunos países de Amé- 
rica Latina, como por ejemplo en México, Honduras, República Dominicana, Paraguay o Nicaragua, la experiencia histórica mostró que la constante manipulación de las reglas de reelección dio lugar a gobiernos caudillistas y autoritarios. Como reacción a estos gobiernos autoritarios, desde 1950 hasta 1990, fue frecuente hallar en las constituciones latinoamericanas prohibiciones absolutas de reelección, es decir la imposibilidad de ejercer la presidencia más de una vez; o limitaciones relativas, como la reelección diferida, que permite a una misma persona volver a postular a la presidencia luego de uno o más períodos.

A partir de mediados de los ochenta, como se ilustra en el Gráfico 1 , esta tendencia restrictiva de la reelección presidencial se revirtió. En lugar de la prohibición absoluta de reelección y la reelección diferida, la mayoría de países de la región estableció la reelección inmediata (o consecutiva) y, desde 2009, en Venezuela, Nicaragua, Ecuador y Bolivia se introdujo la reelección indefinida, dando vía libre para que el presidente pueda presentarse a reelección a voluntad.

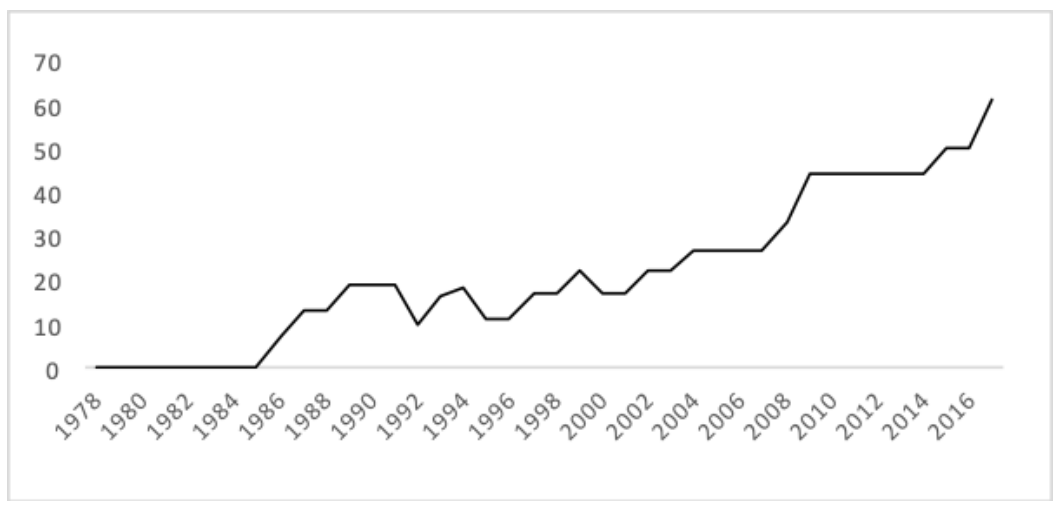

Gráfico 1. Porcentaje de países latinoamericanos democráticos con reelección presidencial inmediata e indefinida (1978-2017). Fuente: elaboración propia.

A pesar de que la reelección indefinida es un esquema institucional que puede llegar a distorsionar e incluso eliminar la alternancia de un gobierno presidencial y democrático, este tipo de reelección ha sido el menos estudiado y debatido. Por ello, el objetivo de esta investigación es precisamente explicar bajo qué condiciones institucionales se adoptó 
la reelección indefinida en Venezuela, Nicaragua, Ecuador y Bolivia. A partir del análisis comparado, destacamos que el híper presidencialismo, la falta de independencia judicial y la flexibilidad de los procedimientos de reforma constitucional facilitaron la eliminación total de los límites constitucionales a la reelección presidencial.

El resto del artículo se estructura de la siguiente manera: en la primera sección presentamos una breve revisión de los argumentos en torno al debate de la reelección presidencial, además de los distintos esquemas que resuelven la continuidad del presidente en el cargo. Desde la segunda a la quinta sección, exploramos los casos nacionales. En la sexta sección analizamos los hallazgos en clave comparada. Finalmente, la última sección destaca las conclusiones.

\section{2. ¿Por qué los límites a la reelección presidencial?}

\subsection{Orígenes y fundamentos}

Los límites a la reelección se definen como las restricciones constitucionales al tiempo y número de mandatos durante los cuales las autoridades electas pueden permanecer en su cargo. El origen de estas restricciones se remonta a las antiguas repúblicas. En Grecia, por ejemplo, las ciudades-estado requerían que los gobernantes "no puedan ejercer el cargo dos veces" y "que la duración de los cargos sea breve". ${ }^{1}$

El debate de la reelección dentro de un sistema republicano y presidencial se planteó originalmente en los Estados Unidos de América (en adelante EEUU) a finales del siglo XVIII. Durante las convenciones constitucionales, se delinearon varios argumentos a favor y en contra de la conveniencia de los límites al mandato del presidente. Aquellos que se mostraron a favor de los límites a la reelección destacaron la importancia de la alternancia democrática para promover el control ciudadano sobre las autoridades y prevenir la tiranía. ${ }^{2}$ Quienes, al contrario, apoyaron la eliminación de los límites destacaron que la posibilidad de reelección au-

1 ARIStóteles (2015), p. 112.

2 Hamilton (2006), p. 216; Stein (1943), pp. 461-463; Petracca (1996), p. 251. 
mentaría los alicientes del gobernante para conducirse honestamente, reduciría las posibilidades de corrupción, premiaría la experiencia en el manejo de los asuntos públicos y respetaría de mejor modo la voluntad de la mayoría. ${ }^{3}$

A pesar de que en el Plan de Virginia se aprobó un proyecto constitucional que originalmente establecía un término de mandato de siete años y la prohibición de reelección, la Constitución de 1787 no incluyó ningún límite formal a la reelección presidencial. No obstante, el transcurso del tiempo instauró como costumbre constitucional la posibilidad de reelegirse por un mandato adicional consecutivo. La reelección inmediata, es decir, por el máximo de dos periodos de cuatro años, permaneció vigente como costumbre constitucional hasta 1940, cuando Roosevelt optó por un tercer periodo de mandato. En 1951, a raíz de la muerte de Roosevelt, se introdujo la Décimo Segunda Enmienda (1951) que formalizó la reelección inmediata.

La realidad de los EEUU contrastó significativamente con lo que sucedió en el resto del continente. En América Latina, desde el origen republicano de los Estados, la mayoría de constituciones instituyeron esquemas de reelección restrictivos. ${ }^{4}$ Por citar un ejemplo, en Colombia (1821) se adoptó la reelección diferida y más adelante la prohibición de la reelección. Durante el siglo XIX, las constituciones ecuatorianas prohibieron la reelección inmediata, con excepción de las constituciones de 1869 y 1878. Lo propio sucedió en Brasil (1891) que prohibió la reelección inmediata. La proscripción de fórmulas permisivas de reelección buscaba prevenir los abusos de poder por parte del ejecutivo. ${ }^{5}$

Aunque los límites constitucionales a la reelección eran comunes, lo propio sucedía con los intentos de evadirlos. ${ }^{6}$ Simón Bolívar, por ejemplo, reivindicó la validez de las restricciones a la reelección, pero pocos años después defendió la presidencia vitalicia como una institución necesaria

3 HUME (1789), p. 171.

4 GINSBURg et al. (2011) p. 1842.

5 Alberdi (1964), p. 282.

6 Véase, por ejemplo, los casos de Juan Rafael Mora en Costa Rica, Bolívar en Perú o del gobernador Rosas en Argentina y Porfirio Díaz y Benito Juárez en México, entre otros. 
para la conducción de las nacientes repúblicas sudamericanas. ${ }^{7}$ En otros casos, las experiencias caudillistas en Costa Rica, Argentina y México ocurridas en el siglo XIX e inicios del XX motivaron la adopción de fórmulas restrictivas como la reelección diferida o la prohibición absoluta de reelección. ${ }^{8}$

Ya a mediados del siglo XX, el debate en los países latinoamericanos se centró en los beneficios de los esquemas restrictivos de reelección como instituciones capaces de limitar el poder del Ejecutivo y consolidar democracias estables. Si bien era necesario instituir límites temporales al mandato del presidente, varios estudiosos estimaron que las fórmulas en extremo restrictivas de reelección -léase la prohibición absoluta de reelección- introducían tensiones entre los poderes públicos y al interior de los partidos políticos. Para Linz, la rigidez en los mandatos limitados en sistemas presidenciales restringía el ámbito de maniobra del ejecutivo y eventualmente conducía a momentos de estancamiento en la política que incentivaban a los actores públicos a actuar al margen de sus potestades constitucionales. La necesidad de producir nuevos liderazgos y desechar aquellos ya consolidados cada cierto tiempo, por otro lado, incrementaba el riesgo de conflictos y desestabilización. ${ }^{9}$

Otros estudios emplearon formulaciones modificadas de las ideas de Linz para justificar y a la vez exponer las debilidades de cada tipo de reelección. ${ }^{10}$ Colomer sostuvo que en un gobierno unificado -aquel en el que un partido político controla el ejecutivo y el legislativo-, la prohibición de reelección presidencial genera un balance más equilibrado entre poderes. ${ }^{11}$ Lijphart, al contrario, se inclinó ante la posibilidad de una reelección, ya sea diferida o inmediata, para prevenir que el presidente en funciones sea indiferente a las preferencias del electorado. ${ }^{12}$ Para Sartori, la posibilidad de reelección inmediata induciría a los presidentes

\footnotetext{
7 Barletta VilLARÁN (2011), p. 34.

8 CAREY (2003) p. 124

9 LinZ Y VALenZUeLA (1994), p. 223.

10 Cheibub (2007), p. 53; MainWARING y Scully (2008), p. 120. 2007

11 Colomer (2003), p. 112.

12 LIJPHART (1990), p. 123.
} 
a hacerse elegir, desbalanceando la competencia electoral. Sin embargo, el profesor italiano estimaba que la prohibición absoluta de reelección tampoco era deseable porque podría debilitar al presidente, sobre todo durante sus últimos años de mandato. ${ }^{13}$

Desde las últimas décadas, el debate en torno a la posibilidad de reelecciones continuas y su armonización con los principios de soberanía y alternancia democrática ha retornado a la palestra, a partir de que varios países de la región flexibilizaron los límites a la reelección y algunos incluso adoptaron la fórmula más permisiva de reelección - la reelección indefinida o eliminación total de las restricciones al tiempo y número de mandatos presidenciales permitidos. Quienes apoyan la relajación de los límites a la reelección argumentan que las restricciones a la reelección son límites artificiales e iliberales que condicionan la toma de decisiones democráticas, violan la igualdad y los derechos políticos, condicionan la plena implementación de los instrumentos internacionales de derechos humanos y limitan los objetivos de programas de gobierno progresistas. ${ }^{14}$

Aquellos que, por el contrario, objetan esta tendencia pro reeleccionista advierten sobre el posible tránsito de democracias no consolidadas e institucionalmente débiles hacia autoritarismos competitivos o regímenes plenamente autoritarios, caracterizando la posibilidad de reelección indefinida como un factor crucial de apuntalamiento del poder presidencial que pone en riesgo el propio carácter alternativo, democrático y republicano del régimen político. ${ }^{15}$ En la misma línea, otros autores señalan que la flexibilización de los límites del mandato presidencial debilita la competencia electoral, la división de poderes, el respeto hacia las libertades $y$, consecuentemente, incrementa los abusos de poder. ${ }^{16}$ Los opositores a la flexibilización de la reelección también hacen notar la utilización an-

13 SARTORI (1996), p. 47.

14 TCP Declaración Constitucional Plurinacional N 0003/2013; TCP Declaración Constitucional Plurinacional N 0194/2015; Entrevista a Ernesto Laclau, “¿Por qué tiene que haber límites a la reelección?”, accedido 16 de julio de 2018, https://www.lanacion.com. ar/1438389-por-que-tiene-que-haber-limites-a-la-reeleccion.

15 SerRafero (1997) p. 15; SeRrafero (2011) pp. 11-12.

16 Bernal-Pulido et al. (2015), p. 16; Brewer-Carías (2009), p. 207; Brewer-Carías (2009A), p. 2; Martínez-Barahona (2010) p. 734, Dixon y Landau (2020), p. 365, Versteeg et al. (2020). 
tojadiza y mañosa del discurso de los derechos humanos para justificar la continuidad en el mandato de presidentes con altos niveles de popularidad y capital político. ${ }^{17}$

Ante la limitada evidencia empírica que informa el debate normativo en torno a la reelección, esta investigación utiliza datos originales para explicar las condiciones que favorecieron la flexibilización de los límites a la reelección presidencial. Esta exploración empírica, sin embargo, requiere primero analizar los diferentes esquemas que resuelven la continuidad del presidente.

\subsection{Tipos de reelección presidencial}

Comúnmente las discusiones en torno a la reelección presidencial suelen sintetizarse de manera dicotómica, confrontando las argumentos histórico-normativos de los defensores y de los detractores de los límites temporales a los mandatos presidenciales. Sin embargo, como se puede apreciar en el Gráfico 2, existen varias fórmulas institucionales que resuelven la continuidad del presidente en el cargo. Estas fórmulas se clasifican a partir del nivel de permisividad que cada tipo de reelección otorga al presidente en ejercicio para optar o no por la reelección.

La prohibición de reelección, ubicada en el extremo izquierdo de la escala de tipos de reelección, imposibilita absolutamente que una persona ejerza la presidencia más de una vez y es, por tanto, la fórmula más restrictiva. Le sigue la reelección diferida que impide que el presidente de turno pueda postularse para un segundo mandato consecutivo. La reelección diferida varía en función de la condición que establece el número de períodos o años que deben transcurrir antes que un candidato pueda volver a postularse. La reelección diferida puede ser abierta, si no limita el número de mandatos no consecutivos permitidos, o cerrada, si condiciona expresamente el número de mandatos no consecutivos du-

17 CDL-AD (2018) 010-e, Reporte sobre límites al mandato presidencial, Comisión de Venecia, adoptado en la Sesión plenaria 114, Venecia, 17 de marzo de 2018. Disponible en: http://www. venice.coe.int/webforms/documents/default.aspx?pdf=CDL-AD(2018)010-e\&lang=RU. Fecha de consulta: 19 de abril de 2019. 


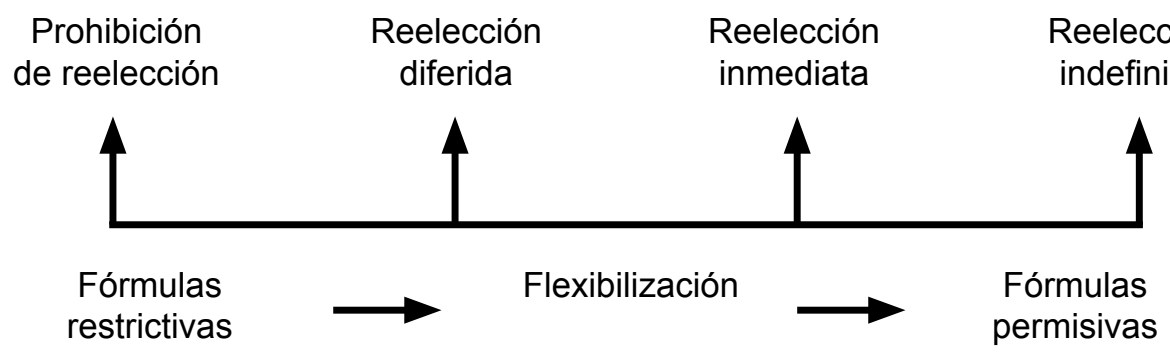

Gráfico 2. Los tipos de reelección. Elaboración propia.

rante los cuales una misma persona puede ejercer la presidencia. La reelección inmediata, en cambio, permite que el presidente en ejercicio pueda presentarse de manera continua a la reelección, aunque por un número acotado de períodos -generalmente dos. En el extremo derecho de la escala de tipos de reelección, la reelección indefinida permite que la misma persona se presente a reelección a perpetuidad.

Debe notarse que esta tipología implica una suerte de continuum que va desde la limitación temporal más fuerte -la prohibición de reelección-, pasando por una limitación algo menos restrictiva, es decir, poder reelegirse pasando varios o al menos un período o número de años, hasta una limitación temporal más débil representada por la reelección inmediata. En este continuum la forma cerrada de la reelección inmediata y de la diferida implican también limitaciones temporales más fuertes que las abiertas.

Lo cierto es que la antípoda de la no reelección vendría a ser la reelección indefinida. A diferencia de los otros tipos de reelección, la reelección indefinida elimina todo tipo de restricción temporal al ejercicio del poder presidencial. Las restricciones a la reelección, de hecho, configuran el llamado principio de alternancia, que consiste esencialmente en limitar la posibilidad de que una misma persona postule indefinidamente al mismo cargo de elección popular. En otras palabras, la reelección indefinida podría anular el principio de alternancia, permitiendo postulaciones a voluntad de la misma persona a la presidencia, sin restricción temporal alguna.

En las siguientes secciones, exploramos los casos nacionales de manera cronológica. Como adelantamos, centramos nuestro análisis en tres 
factores que coadyuvaron a la instauración de la reelección indefinida: a) los poderes constitucionales del presidente, b) la independencia judicial y c) la flexibilidad de los mecanismos de reforma constitucional.

\section{La reelección indefinida en Venezuela (2009)}

En febrero de 1992, Hugo Chávez, comandante de paracaidistas del ejército venezolano, lideró un golpe de Estado en contra del gobierno de Carlos Andrés Pérez. Aunque el golpe orquestado por Chávez fracasó, su irrupción en el escenario político fue exitosa. Para 1998, Chávez fue electo presidente por el 68\% del electorado. En 1999, Chávez llevó a cabo el referéndum para la convocatoria de la Asamblea Constituyente y en diciembre del mismo año, también vía referéndum, se aprobó el nuevo texto constitucional que le permitía optar por una reelección consecutiva.

En 2006, Chávez fue reelecto y en 2007 intentó de manera fallida reformar la constitución para introducir la reelección indefinida. Luego del primer caso, Chávez buscó nuevamente una enmienda a la Constitución a finales de 2008, poco después de las elecciones regionales y locales. En 2009, la Constitución venezolana fue reformada abriendo la posibilidad a la reelección indefinida.

\subsection{Poderes constitucionales del presidente}

Tradicionalmente, el ejecutivo venezolano ha sido caracterizado como un actor institucionalmente débil: con poder de veto fácilmente superable por la Asamblea, habilitaciones (o delegaciones) legislativas restringidas a materias económicas y financieras, sin facultades para activar mecanismos de democracia directa, sin potestades para iniciar reformas a la constitución y sin opción de reelección inmediata. ${ }^{18} \mathrm{~A}$ partir de la aprobación de la Constitución de 1999, las capacidades del presidente se robustecieron de manera importante. El presidente, por ejemplo, adquirió la capacidad para dictar decretos-leyes previa ley habilitante emitida por la Asamblea Nacional, convocar a referéndums consultivos, abrogatorios

18 Coppedge (1998), p. 337; Mainwaring y Shugart, (1997), p. 45. 
de leyes y de aprobación de tratados internacionales, ejercer la máxima autoridad de las fuerzas armadas e incluso disolver la Asamblea Nacional.

Otro ejemplo del fortalecimiento del poder presidencial es la ampliación del término de mandato. Según la Constitución de 1961, el mandato presidencial era de cinco años con la posibilidad de reelegirse luego de luego de diez años siguientes a la terminación de su primer mandato, es decir, se establecía un esquema de reelección diferida. La Constitución de 1999 rompió este cerrojo restrictivo y abrió la puerta a un período de mandato que podía llegar a los doce años, en caso de reelección. Esta continuidad temporal, en contraposición con periodos de mandato acotados, resulta decisiva para que los presidentes desarrollen sus políticas públicas.

Quizás la facultad más importante para explicar la instauración de la reelección indefinida es la facultad de iniciativa del presidente para proponer enmiendas y reformas constitucionales o en su defecto convocar a una Asamblea Nacional Constituyente de plenos poderes encargada de redactar una nueva constitución. La Constitución de 1961 reservaba la iniciativa para proponer enmiendas constitucionales o reformas generales para la cuarta parte de una de las Cámaras del legislativo o a la cuarta parte de las Asambleas Legislativas de los Estados. La Constitución de 1999, en cambio, modificó sustancialmente la iniciativa y tramitación de enmiendas y reformas. Si bien todos los casos de enmienda y reforma deben someterse a referendo popular aprobatorio, la iniciativa que tienen el ejecutivo y el legislativo para proponer enmiendas y reformas resulta esencial para entender el cambio constitucional orientado a la reelección indefinida.

\subsection{Independencia judicial del órgano que ejerce control jurisdiccional}

La Sala Constitucional del Tribunal Supremo de Justicia (TSJ) tuvo un papel protagónico que permitió viabilizar la adopción de la reelección indefinida. Justo antes de la aprobación mediante referéndum de la enmienda de la reelección indefinida, la Sala Constitucional conoció y resolvió una acción de interpretación en la que se pronunció sobre dos cues- 
tiones. En primer lugar, la Sala resolvió si el procedimiento de enmienda se encontraba sujeto a la restricción establecida en el artículo 345 de la Constitución que indica "que la iniciativa de reforma constitucional revisada no podrá presentarse de nuevo en un mismo período constitucional a la Asamblea Nacional". En segundo lugar, si podía enmendarse la Constitución para adoptar la reelección indefinida, sin afectar el principio constitucional de alternancia democrática.

En torno a la primera cuestión, la Sala Constitucional señaló que la limitante establecida en el artículo 345 de la Constitución no era aplicable al procedimiento de la enmienda. A través de una interpretación literalista, el TSJ consideró que la enmienda y la reforma son procedimientos distintos, cuya tramitación, requisitos y limitaciones se encuentran regulados en capítulos diferentes del texto constitucional. En esta línea, el TSJ sostuvo que el artículo 345 estaba dirigido a limitar que la Asamblea Nacional debata una reforma rechazada por la ciudadanía, lo cual, según la Sala, no estaba prescrito para el trámite de enmienda. En consecuencia, el TSJ estimó que la enmienda para instaurar la reelección no se encontraba sujeta a la restricción que proscribía la tramitación de una reforma improbada durante un mismo período constitucional de la Asamblea Nacional.

Debe recordarse que el primer intento para adoptar la reelección indefinida se tramitó entre 2006 y 2007 mediante el procedimiento de reforma (art. 342 de la Constitución), siendo posteriormente rechazada mediante referendo. En 2009, ante la imposibilidad de utilizar el procedimiento de reforma por segunda vez durante el mismo mandato constitucional, la reelección indefinida se tramitó a través del procedimiento de enmienda constitucional (art. 340 de la Constitución).

En cuanto al segundo problema jurídico, la compatibilidad de la reelección indefinida con un sistema de gobierno democrático y alternativo, el TSJ evocó la figura de Bolívar y su influencia en la Constitución de Angostura de 1819, que establecía la posibilidad de una reelección para el presidente. A partir de un breve análisis de las ideas de Hamilton y Sartori, el TSJ resaltó la posibilidad de reelección como un incentivo que recompensa al buen gobernante. Tras citar su propia jurisprudencia, 
los magistrados indicaron que la adopción de la reelección indefinida no comporta un cambio de régimen o forma de Estado, sino que amplía los derechos de los ciudadanos y el control ciudadano de los gobernantes.

Respecto de la alternancia democrática, el TSJ afirmó que la reelección indefinida no suponía vulneración alguna al principio de alternancia, siempre y cuando se garanticen elecciones periódicas. Este argumento evidencia una lógica equívoca, al confundir el carácter alternativo -es decir, el ejercicio de un cargo por personas distintas- con el carácter electivo de un gobierno democrático que se traduce en una designación fruto de una elección popular. El Tribunal agregó que la existencia de mecanismos como la revocatoria de mandato prevendrían la posibilidad de extender el mandato presidencial a perpetuidad, sin contar con el respaldo del pueblo.

\subsection{Flexibilidad del mecanismo de reforma constitucional}

La Constitución venezolana de 2009 consagra un sistema de reforma escalonado que se estructura a partir de tres mecanismos: la enmienda, la reforma (parcial) y la asamblea constituyente (reforma total). ${ }^{19} \mathrm{La}$ Tabla 1 resume el objeto, límites, iniciativa, trámite y aprobación de los tres mecanismos de cambio constitucional. En esta sección, analizamos exclusivamente la enmienda dado que éste fue el mecanismo empleado para introducir la reelección indefinida en 2009.

En comparación con la reforma y la asamblea constituyente, la enmienda es un mecanismo más flexible de cambio constitucional. Los umbrales requeridos en la Asamblea Nacional para la iniciativa, así como el trámite en dos discusiones y aprobación en sede legislativa, son menos gravosos que aquellos previstos para la reforma parcial y la asamblea constituyente.

A pesar de su flexibilidad relativa frente a otros mecanismos de cambio constitucional, la enmienda requiere el consenso de varios actores políticos. Según el artículo 341 de la Constitución, la iniciativa de en-

19 Constitución de la República Bolivariana de Venezuela, artículos 342 y ss. 
Tabla 1. Procedimientos de reforma de la Constitución venezolana de 1999

\begin{tabular}{|c|c|c|c|}
\hline & Enmienda & Reforma & Asamblea Constituyente \\
\hline Objeto & $\begin{array}{l}\text { Adición o modificación } \\
\text { de varios artículos }\end{array}$ & $\begin{array}{l}\text { Revisión parcial y sus- } \\
\text { titución de una o varias } \\
\text { normas }\end{array}$ & $\begin{array}{l}\text { Transformar el Estado, } \\
\text { establecer un nuevo orden } \\
\text { jurídico y redactar una } \\
\text { nueva constitución }\end{array}$ \\
\hline Límite & $\begin{array}{l}\text { No puede alterar la es- } \\
\text { tructura fundamental de } \\
\text { la Constitución }\end{array}$ & $\begin{array}{l}\text { No puede alterar la es- } \\
\text { tructura, ni los principios } \\
\text { de la Constitución }\end{array}$ & $\begin{array}{l}\text { Sin límite proveniente de } \\
\text { poderes constituidos }\end{array}$ \\
\hline Iniciativa & $\begin{array}{l}\text { a) } 15 \% \text { ciudadanos, } \\
\text { b) } 30 \% \text { de integrantes } \\
\text { de la Asamblea Nacional } \\
\text { (AN), o } \\
\text { c) Presidente }\end{array}$ & $\begin{array}{l}\text { a) } 15 \% \text { de electores, } \\
\text { b) mayoría (simple) de } \\
\text { integrantes de la AN, o } \\
\text { c) Presidente }\end{array}$ & $\begin{array}{l}\text { a) Presidente, } \\
\text { b) mayoría calificada (2/3) } \\
\text { de los integrantes de la } \\
\text { AN, o } \\
\text { c) } 15 \% \text { Ciudadanos }\end{array}$ \\
\hline Trámite & $\begin{array}{l}\text { Mismo procedimiento de } \\
\text { formación de las leyes ( } 2 \\
\text { discusiones en la AN en } \\
2 \text { días distintos) }\end{array}$ & $\begin{array}{l}3 \text { discusiones (por título } \\
\text { o capítulo y por artículo) } \\
\text { hasta en } 2 \text { años }\end{array}$ & $\mathrm{N} / \mathrm{A}$ \\
\hline $\begin{array}{l}\text { Aprobación } \\
\text { legislativa }\end{array}$ & $\begin{array}{l}\text { Mayoría (simple) de } \\
\text { integrantes de la AN }\end{array}$ & $\begin{array}{l}\text { Mayoría calificada }(2 / 3) \\
\text { de los integrantes de la } \\
\text { AN }\end{array}$ & $\mathrm{N} / \mathrm{A}$ \\
\hline $\begin{array}{l}\text { Aprobación } \\
\text { popular }\end{array}$ & $\begin{array}{l}\text { Poder electoral somete a } \\
\text { referendo y se aprueba } \\
\text { por mayoría simple e }\end{array}$ & $\begin{array}{l}\text { Poder electoral some- } \\
\text { te a referendo (puede } \\
\text { votarse por separado) y } \\
\text { se aprueba con mayoría } \\
\text { simple }\end{array}$ & Mayoría simple \\
\hline
\end{tabular}

Fuente: Elaboración propia.

mienda puede partir del quince por ciento de los ciudadanos inscritos en el Registro Civil y Electoral, del treinta por ciento de los integrantes de la Asamblea Nacional o del presidente. Si la iniciativa proviene de la Asamblea Nacional, la enmienda debe aprobarse con la votación de la mayoría simple de los integrantes, siguiendo el procedimiento de formación de leyes consagrado en los artículos 207 y siguientes de la Constitución. Una vez aprobada en sede legislativa, la enmienda requiere de la ratificación popular en referéndum.

Por pedido expreso del ejecutivo, la enmienda que instauró la reelección indefinida se tramitó por vía legislativa. ${ }^{20} \mathrm{~A}$ finales de noviembre

20 A pesar de haber iniciado la recolección de firmas por parte de la ciudadanía, la urgencia de la enmienda obligó al PSUV a tramitar la enmienda en sede legislativa. 
de 2008, durante una alocución transmitida en cadena nacional, Hugo Chávez manifestó: "yo les doy mi autorización al PSUV y al pueblo venezolano para que inicien el debate y las acciones para lograr la enmienda constitucional y la reelección como Presidente de la República". ${ }^{21}$ Chávez también dejó claro que la enmienda debía tramitarse y aprobarse de manera inmediata: "solo les voy a pedir algo primero, si es que lo vamos a hacer es para ganar la enmienda constitucional y ganar de manera abrumadora por nocaut y, en segundo lugar, si lo vamos a hacer, hagámoslo rápido, yo de verdad no quisiera pasar el año 2009 discutiendo". ${ }^{22}$

El pedido de Chávez tuvo eco inmediato en el legislativo, en donde su partido el Partido Socialista Unido de Venezuela (PSUV) sumado a otros aliados políticos ejercían un control casi hegemónico del 98 por ciento de escaños. Cilia Flores, congresista por el PSUV y Presidenta de la Asamblea Nacional, presentó la propuesta de enmienda el 9 de diciembre de 2008. Diez días más tarde, el proyecto que originalmente preveía ampliar la reelección únicamente para el presidente fue aprobado en primera discusión con una abrumadora mayoría de 141 de un total de 167 votos. ${ }^{23}$

A inicios de 2009, Chávez planteó que la reelección indefinida debía ampliarse para todos los cargos de elección popular como gobernadores, alcaldes y legisladores. ${ }^{24}$ Esta propuesta surgió como una respuesta política a resquebrajamientos al interior del PSUV ${ }^{25}$ y también a la derrota electoral del chavismo en gobernaciones como Carabobo, Miranda,

21 Maye Primera, "Chávez reabre el proceso para su reelección indefinida", El País, 1 de diciembre de 2008. Disponible en: https://elpais.com/diario/2008/12/01/internacional/1228086005_850215. html.

22 "Chávez: Hoy comienza la campaña por la enmienda constitucional". Disponible en: http:// www.psuv.org.ve/temas/noticias/Chavez-Hoy-comienza-la-campana-por-la-enmienda-constitucional/\#.W4BxFuhKjlU.

23 Proyecto de Enmienda al Artículo 230 de la Constitución de la República Bolivariana de Venezuela. Disponible en: https://aldiavenezuela.microjuris.com/2008/12/20/proyecto-de-enmienda-al-articulo-230-de-la-constitucion-de-la-republica-bolivariana-de-venezuela/.

24 Maye Primera, "Luz verde a la reforma constitucional para la reelección indefinida de Chávez", El País, 15 de enero de 2009. Disponible en: https://elpais.com/internacional/2009/01/15/ actualidad/1231974005_850215.html.

25 Durante las elecciones de resquebrajamiento interno del PSUV, que ocasionó la separación de partidos con fuerzas marginales como Patria Para Todos o el Partido Comunista de Venezuela de la coalición chavista. 
Nueva Esparta, Táchira y Zulia y de importantes centros urbanos como Sucre, durante las elecciones seccionales de 2008. La Asamblea Nacional acogió la propuesta y con 146 de 167 votos aprobó el texto de la pregunta que sería sometida al referendo.

El 16 de enero de 2009 el texto de la pregunta fue remitido al Consejo Nacional Electoral y ese mismo día se anunció que el referéndum ratificatorio se celebraría el 15 de febrero. La enmienda fue finalmente aprobada con el 54,8 por ciento de votos por el sí y el 45,7 por ciento por el no, un resultado relativamente holgado que no había sido previsto por los encuestadores locales. ${ }^{26}$

\section{La reelección indefinida en Nicaragua (2009 y 2014)}

Daniel Ortega, líder revolucionario sandinista, saltó a la palestra pública luego de la caída del régimen somocista. Durante la transición a la democracia, Ortega formó parte de la Junta de Gobierno de Reconstrucción Nacional y en 1985 fue electo presidente. En 1996 y 2001 fue derrotado, pero triunfó en las elecciones presidenciales de 2006.

En 2009, la Corte Suprema de Nicaragua resolvió un recurso de amparo interpuesto por Ortega y 109 alcaldes del Frente Sandinista de Liberación Nacional (FSLN) que declaró inaplicable la prohibición de reelección establecida por la reforma constitucional de 1995. Esto le permitió a Ortega ocupar por tercera vez la presidencia, luego de vencer en las controvertidas elecciones de 2011. En 2014, con el apoyo legislativo del FSLN, Ortega logró reformar la Constitución e introducir la reelección indefinida.

\subsection{Poderes constitucionales del presidente}

La Constitución nicaragüense de 1987 estableció importantes facultades legislativas y no legislativas para el presidente, como, por ejemplo, vetar total y parcialmente las leyes, dictar decretos ejecutivos "de aplica-

26 Resultados del referendo aprobatorio de la enmienda constitucional. Disponible en: http:// pdba.georgetown.edu/Elecdata/Venezuela/ref09.html. 
ción general" para asuntos de carácter administrativo ${ }^{27}$, nombrar a los ministros, viceministros, procurador general del Estado y presidentes de los entes autónomos y gubernamentales, con la ratificación de la Asamblea Nacional, proponer listas para la elección de magistrados de la Corte Suprema de Justicia, del Consejo Supremo Electoral, de superintendentes de bancos y servicios públicos, de los miembros del Consejo de la Contraloría, del procurador para la defensa de los derechos humanos, entre otros funcionarios, e iniciar reformas parciales a la constitución.

Esta última facultad está íntimamente ligada con la reforma que introdujo la reelección indefinido en 2014 . Al respecto, es importante destacar que la Constitución dispone que la iniciativa de reforma constitucional debe ser discutida, en todos los casos, en dos legislaturas y requiere el 60 por ciento de votos del total de miembros de la Asamblea Nacional. ${ }^{28}$ La iniciativa de reforma, así como la fortaleza política de Ortega en el legislativo fueron determinantes al momento de buscar la adopción de reelección indefinida, a través del procedimiento de reforma parcial. Sin embargo, cabe destacar que la reforma que incluyó la reelección indefinida en 2014 no nació de la iniciativa del ejecutivo, sino de 63 diputados sandinistas en la AN. ${ }^{29}$

\subsection{Independencia judicial del órgano que ejerce control jurisdiccional}

En 2009, la falta de apoyo legislativo y popular llevó a Ortega a buscar la reelección en arenas extraparlamentarias. La vía judicial, en un contexto en el que los propios jueces constitucionales profesaban su ideología política - en la mayoría de los casos afín al sandinismo - sin tapujos, se presentó como un atajo adecuado para lograr la reelección, sin tener que activar procedimientos de reforma formal de la constitución. ${ }^{30}$ El mismo

27 Ibíd. artículo 150 (reforma constitucional de 1995).

28 Ibíd., artículos 191 y 192.

29 Resolución Junta Directiva N 10-2013. Disponible en: http://legislacion.asamblea.gob.ni/Diariodebate.nsf/76ed72912dd57e570625698c00773f5d/5e1dd1dcc062f63906257ca800569b33.

30 Martinez-Barahona (2010) p. 734.

BRENES (2010) p. 55. 
año, la Corte Suprema de Nicaragua resolvió un recurso de amparo interpuesto por Ortega y 109 alcaldes del Frente Sandinista de Liberación Nacional (FSLN), el partido de Ortega, y declaró inaplicable la prohibición de reelección establecida por los artículos 147 y 178 de la Constitución.

A partir de una interpretación muy similar a aquella dictada por la Sala IV en Costa Rica en 2003, la Sala de lo Constitucional de la Corte Suprema de Justicia declaró inaplicables las reglas expresas de la Constitución que limitaban la reelección de Ortega. Esta sentencia le abrió las puertas a Ortega para convertirse en el primer presidente reelecto en Nicaragua desde el retorno a la democracia en 1985.

El 19 de octubre de 2009, la Sala de lo Constitucional de la CSJ, conformada por los magistrados Francisco Rosales, Rafael Solís, Yadira Centeno, Ligia Molina y Armengol Cuadra, todos afines al FSLN, conoció y resolvió el recurso de amparo de Daniel Ortega, presentado conjuntamente con 109 alcaldes sandinistas. En su recurso, Ortega impugnó la resolución dictada por el Consejo Supremo Electoral que rechazó, por falta de competencia, la solicitud para que se declaren inaplicables las interdicciones constantes en las leyes electorales que les impedían postular para un tercer periodo de mandato, planteada por el propio Ortega.

El recurso interpuesto por Ortega se fundamentó en la aplicación preferente del principio constitucional de igualdad incondicional de los derechos políticos frente a los límites a la reelección establecidas en la propia Constitución y en la Ley Electoral. ${ }^{31}$ A criterio de los recurrentes, los límites a la reelección violaban la igualdad en tanto eran aplicables solo para unos cargos de elección popular (presidente, vicepresidente y alcaldes) y no para otros (diputados de la AN, del Parlamento Centroamericano y los miembros de los Consejo de las Regiones). Los límites a la reelección, añadía el recurso, impedían el ejercicio pleno de los derechos políticos, dado que obstaculizaban la participación de las autoridades en ejercicio en los asuntos políticos de la nación.

En su fallo, la CSJ sostuvo la existencia de una antinomia constitucional entre el principio de igualdad y los artículos que limitaban la ree-

31 Sentencia No. 504-2009 de la Sala Cn. 
lección del presidente y los alcaldes. A través de una lectura disgregada de la Constitución, la Corte consideró que los derechos políticos -entre ellos, participar en los asuntos públicos, en la gestión estatal y el derecho a elegir y ser elegidos- solo pueden ser limitados en virtud de la edad o por la suspensión de los derechos ciudadanos mediante sentencia firme. Asimismo, la Corte estimó la prevalencia interpretativa de los principios constitucionales por sobre el resto de disposiciones constitucionales -es decir, la primacía del principio de igualdad y no discriminación por sobre las reglas que limitaban la reelección presidencial. ${ }^{32}$

En la misma línea, la Corte se refirió al principio de soberanía popular y autodeterminación, entendiéndolo como la voluntad del pueblo que "establece los procedimientos y límites que, en el futuro, encuadrarán la manifestación de esa misma voluntad". ${ }^{33}$ La Constitución de 1987, carente de limitaciones a la reelección, encarnaba esta voluntad suprema y soberana que, a consideración de Corte, no podía ser limitado incluso por las propias normas constitucionales.

Sobre la base de estos fundamentos, la CSJ resolvió que las prohibiciones a la reelección, contenidas en los artículos 147 y 178 de la Constitución, así como en la Ley Electoral, eran inaplicables por discriminatorias y que únicamente la voluntad del pueblo soberano, expresada mediante elecciones auténticas y periódicas, por sufragio universal y libre podrían limitar el derecho a la reelección de las autoridades.

\subsection{Flexibilidad del mecanismo de reforma constitucional}

La Constitución nicaragüense establece la posibilidad de reforma parcial o total. ${ }^{34}$ En el caso de la reforma total, la iniciativa corresponde a la mayoría absoluta (mitad más uno) de los diputados de la AN. La reforma parcial, en cambio, requiere la iniciativa del Presidente de la República o de un tercio de los diputados de la AN. En ambos casos, el proyecto de reforma debe ser tramitado por una comisión especial de la $\mathrm{AN}$, en un plazo

32 Sentencia No. 504-2009 de la Sala Cn.

33 Sentencia No. 504-2009 de la Sala Cn., p. 20.

34 Constitución Política de Nicaragua, artículos 192 y ss. 
Tabla 2. Procedimientos de reforma de la Constitución venezolana de 1999

\begin{tabular}{|lll|}
\hline & Reforma parcial & Reforma total \\
\hline Objeto & Modificación de uno o varios artículos & $\begin{array}{l}\text { Modificación completa de la constitu- } \\
\text { ción }\end{array}$ \\
Iniciativa & $\begin{array}{l}\text { a) Presidente o b) } 1 / 3 \text { de los diputa- } \\
\text { dos de la AN }\end{array}$ & $\begin{array}{l}\text { Mitad más uno de los diputados de la } \\
\text { AN }\end{array}$ \\
Trámite & Discusión en dos legislaturas en la & $\begin{array}{l}\text { Discusión en dos legislaturas y con- } \\
\text { vocatoria a elecciones de Asamblea }\end{array}$ \\
Aprobación & AN & Nacional Constituyente
\end{tabular}

Fuente: elaboración propia.

no mayor a 60 días y aprobado con el voto favorable del 60 por ciento de los diputados en dos legislaturas. ${ }^{35}$ Como resumimos en la Tabla 2, luego de su aprobación, la reforma parcial debe ser promulgada por el presidente de la República, sin lugar a veto. Precisamente, la reforma parcial fue el mecanismo utilizado para introducir la reelección indefinida.

Desde una perspectiva procedimental, el trámite de la reforma parcial configura un escenario institucional que permite realizar modificaciones a la Constitución con relativa flexibilidad en contextos de gobiernos unificados. ${ }^{36}$ Según el diseño constitucional, la AN es el único jugador con poder de veto sobre la iniciativa de reforma proveniente del Ejecutivo, de tal modo que un gobierno de mayoría con alta disciplina partidista no tendría mayores problemas en alterar el status quo constitucional. De hecho, las seis reformas parciales realizadas a la Constitución de 1987 - 1990, 1995, 2000, 2004, 2005 y 2014 - fueron aprobadas durante el mandato de presidentes cuyo partido político logró más del 50 por ciento de escaños en el legislativo.

Al contrario, en los de gobiernos divididos, como el de Arnoldo Alemán (1997-2002) que contó con el 47 por ciento de escaños en el legislativo y el segundo mandato de Daniel Ortega (2006 - 2010) que logró el 41 por ciento de escaños, los intentos de reformas parciales a la constitución por vía legislativa no prosperaron.

35 Cada legislatura comienza el 10 de enero y termina el 15 de diciembre del año en curso.

36 Es decir, aquel en el cual el partido del presidente controla la mayoría de escaños legislativos. 
En suma, a pesar de que la reelección indefinida ya había sido instituida vía interpretación, Ortega buscó una nueva reforma parcial que confirmara definitivamente la reelección indefinida. En 2014, ya como un presidente mayoritario y popular, Ortega no dudó en activar el procedimiento de reforma de la Constitución en la arena parlamentaria. EI hecho de contar con una mayoría legislativa garantizó la aprobación de la reforma en los términos establecidos por el ejecutivo. En 2017, Ortega fue reelecto para su cuarto mandato presidencial; el tercero de manera consecutiva. De finalizar su periodo en 2022, Ortega habrá ejercido la presidencia por más de 20 años.

\section{La reelección presidencial indefinida en Ecuador (2015)}

Rafael Correa, economista y profesor universitario, llegó al poder en 2006, tras un breve paso por el Ministerio de Economía durante el gobierno interino de Alfredo Palacio. Bajo la bandera de la Revolución Ciudadana, Correa plegó todos sus esfuerzos para llevar a cabo una asamblea constituyente encargada de redactar una nueva constitución que sería aprobada mediante referéndum en 2008. Esta Constitución abrió la posibilidad de reelección presidencial para un segundo mandato consecutivo. Los mandatos presidenciales consecutivos, según interpretaciones de la Corte Constitucional, debían computarse a partir de la entrada en vigencia de la Constitución de 2008.

En 2009, Correa fue elegido presidente bajo el nuevo marco constitucional y en 2013 logró la reelección consecutiva. A mediados de 2014, Gabriela Rivadeneira, la presidenta de la Asamblea Nacional y una de las principales dirigentes de Alianza País, el partido de Correa, presentó ante la Corte Constitucional un proyecto de enmienda a la Constitución que incluía entre otras cosas la reelección indefinida. Luego del dictamen favorable de la Corte Constitucional, la enmienda constitucional fue aprobada en sede legislativa con el voto mayoritario de los miembros de Alianza País. Ante la incertidumbre electoral y una transitoria hecha a la medida que le impedía postular para las elecciones de 2017, Correa declinó su candidatura e impulsó la de su delfín, Lenín Moreno. 


\subsection{Poderes constitucionales del presidente}

Bajo la Constitución Política de 1978, el presidente era un actor que tenía importantes poderes legislativos, pero poderes no legislativos más bien débiles. ${ }^{37}$ Esta situación se mantuvo con la Constitución de 1998, pero como veremos, se transformó con la Constitución del 2008, la cual fortaleció aún más los poderes legislativos e incrementó los poderes no legislativos. Además de las tradicionales capacidades para vetar las leyes, dictar reglamentos o nombrar y remover a los ministros, la Constitución de 2008 le otorgó al presidente facultades inéditas que le permiten, por ejemplo, disolver la asamblea nacional o formular las políticas monetaria, crediticia, cambiaria y financiera, por citar dos ejemplos.

La Constitución del 2008 fortaleció indirectamente al ejecutivo mediante el debilitamiento del legislativo. En efecto, esta Constitución crea una Función de Transparencia y Control Social que junto a la Función Electoral se añade a las funciones clásicas, ejecutivo, legislativo y judicial. Esta Función de Transparencia asume las competencias constitucionales, antes radicadas en el legislativo, para designar mediante ternas o concursos a los titulares del Consejo de la Judicatura, órganos de control, Defensor del Pueblo, Defensor Público, Procuraduría y titulares de la Función Electoral. En Ecuador, bajo un gobierno mayoritario durante los períodos de Correa, este diseño institucional permitió al presidente, vía cooptación de los miembros del Consejo que preside esta función, incidir decisivamente en la designación de todas estas autoridades, sin tener casi que contar con el apoyo legislativo.

Respecto del cambio constitucional orientado a la reelección presidencial indefinida, es importante notar que, mientras la Constitución de 1998 exigía una calificación legislativa previa para que el presidente pueda proponer un referéndum para reformar la Constitución, la Constitución del 2008 hace depender tal atribución exclusivamente de una calificación de la Corte Constitucional. En consecuencia, una corte alineada al presidente puede dar curso a cualquier reforma constitucional que el ejecutivo

37 Shugart y CAREY (1992), p. 57. 
plantee, mediante una interpretación funcional.

En resumen, al examinar el desarrollo de las facultades constitucionales del presidente previo a la adopción de la reelección indefinida, resulta muy claro que éstas se fortalecieron muy significativamente. De esta forma se generó una realidad institucional subordinada al ejecutivo que, como señalaremos más adelante, viabilizó la reforma.

\subsection{Independencia judicial del órgano que ejerce control jurisdiccional}

La Corte Constitucional desarrolló una actuación sometida a las políticas y decisiones del Ejecutivo. Por ejemplo, durante diez años la Corte no negó ni una solo declaratoria de estado de excepción por parte del Presidente Correa, cuando en realidad muchos de ellas, aunque convenientes para el gobierno, se referían a situaciones que no cumplían los estándares constitucionales para su declaratoria. En esa misma línea, numerosas leyes y decretos relativos a asuntos económicos, comunicacionales, electorales y de muy diversa índole no fueron objeto de efectivo control constitucional. ${ }^{38}$ También en los procesos judiciales revisados por la Corte Constitucional en que el Estado era parte, éste gozaba de altas tasas de éxito en sus demandas, especialmente frente a los particulares. ${ }^{39}$

Si no se restringe derechos, ni se altera los elementos constitutivos del Estado, ni la estructura de la Constitución, según el artículo 441 de la carta fundamental del Ecuador, el procedimiento de enmienda para introducir la reelección indefinida se puede adelantar por aprobación legislativa, sin necesidad de ratificación mediante consulta popular. Ésta fue justamente la posición sostenida por el Presidente Correa y su partido Alianza País desde el 2014, considerando además que contaba con la mayoría legislativa para llevarla a efecto. La Corte Constitucional, sin mayor análisis jurídico, no dudó en legitimar este procedimiento. ${ }^{40}$

38 GRIJALVA et al (2016), p. 54.

39 Castro-Montero y van Diuck (2017) p. 396; Castro-Montero y Proaño (2018) p. 57.

40 Ecuador, Corte Constitucional, Dictamen 001-14-DRC-CC, publicado en el Registro Oficial No. 9 de 10 de noviembre de 2014 . 
De esta forma, la Corte Constitucional fue totalmente funcional al Ejecutivo y mediante un dictamen de constitucionalidad definió que el trámite de enmienda (artículo 441 de la Constitución) era el procedimiento adecuado para introducir la reelección indefinida en la Constitución. La tesis central de la Corte, haciéndose eco de la del ejecutivo, fue que la reelección indefinida no restringía, sino que ampliaba derechos constitucionales en tanto admitía que los electores eligieran libremente, sin limitaciones, y permitía a quien ejercía un cargo de elección popular volver a presentarse como candidato sin restricción temporal alguna..$^{41}$ La Corte, a través de una interpretación literalista, añadió que -a diferencia de la Constitución de 1998 que establecía en su artículo 1 el carácter alternativo del gobierno- la Constitución de 2008 no incluía la alternancia como un elemento constitutivo del Estado. Sin embargo, en un razonamiento equívoco, que confunde el carácter alternativo y electivo del gobierno, la Corte estimó que el solo hecho de que el pueblo elija a sus representantes a través de elecciones libres garantizaba la alternancia democrática.

Además de la reelección indefinida, el Ejecutivo planteó simultáneamente otras reformas constitucionales relativas a la restricción de derechos de sindicalización, negociación colectiva y huelga de trabajadores públicos; restringió la participación en consultas populares, fortaleció el rol de las Fuerzas Armadas en el orden interno, y disminuyó las competencias de la Contraloría General del Estado. Como puede apreciarse estas reformas constitucionales apuntaron al fortalecimiento del poder del ejecutivo y a la restricción de derechos fundamentales, incluyendo los de participación política. Corresponden por tanto a una lógica de concentración del poder en el cual, como venimos demostrando, se inscribe la instauración de la reelección indefinida.

\subsection{Flexibilidad del mecanismo de reforma constitucional}

La Constitución ecuatoriana de 2008 contempla tres procedimientos de reforma constitucional: la enmienda, la reforma parcial y la asamblea

41 Dictamen 001-14-DRC-CC, dictado dentro del caso No. 0001-14-RC (2014). 
Tabla 3. Procedimientos de reforma de la Constitución ecuatoriana

\begin{tabular}{|c|c|c|c|}
\hline & Enmienda & Reforma parcial & $\begin{array}{l}\text { Asamblea } \\
\text { Constituyente }\end{array}$ \\
\hline Iniciativa & $\begin{array}{l}\text { a) Presidente, b) } 8 \% \text { de per- } \\
\text { sonas o c) } 1 / 3 \text { de miembros } \\
\text { de AN }\end{array}$ & $\begin{array}{l}\text { a) Presidente, b) } 1 \% \text { de } \\
\text { personas o c) mayoría } \\
\text { simple de miembros de } \\
\text { AN }\end{array}$ & $\begin{array}{l}\text { a) Presidente, b) } 2 / 3 \\
\text { de miembros de la } A N \text {, } \\
\text { c) } 12 \% \text { de personas }\end{array}$ \\
\hline Trámite & $\begin{array}{l}\text { En caso de iniciativa de la } \\
\text { AN, será tramitado en } 2 \\
\text { debates (el } 2 \text { do debate se } \\
\text { realizará en los } 30 \text { días si- } \\
\text { guientes al año de realizado } \\
\text { el 1ro) }\end{array}$ & $\begin{array}{l}2 \text { debates en la AN (el } \\
2 \text { do debate se realizará al } \\
\text { menos } 90 \text { días después } \\
\text { del } 1 \text { ro). }\end{array}$ & $\mathrm{N} / \mathrm{A}$ \\
\hline Límites & $\begin{array}{l}\text { No puede alterar la estructu- } \\
\text { ra fundamental de la cons- } \\
\text { titución, ni los elementos } \\
\text { constitutivos del Estado, no } \\
\text { puede establecer restriccio- } \\
\text { nes a derechos y garantías } \\
\text { jurisdiccionales y no puede } \\
\text { modificar el procedimiento } \\
\text { de reforma constitucional }\end{array}$ & $\begin{array}{l}\text { No puede establecer } \\
\text { restricciones a derechos } \\
\text { y garantías jurisdicciona- } \\
\text { les y no puede modificar } \\
\text { el procedimientos de } \\
\text { reforma constitucional }\end{array}$ & $\mathrm{N} / \mathrm{A}$ \\
\hline Aprobación & $\begin{array}{l}\text { a) Referéndum constitucio- } \\
\text { nal (mayoría simple) en caso } \\
\text { de iniciativa del presidente } \\
\text { o ciudadana o b) } 2 / 3 \text { de } \\
\text { miembros de la AN en caso } \\
\text { de iniciativa de la AN }\end{array}$ & $\begin{array}{l}\text { Referéndum constitucio- } \\
\text { nal (mayoría simple) }\end{array}$ & $\begin{array}{l}\text { Referéndum cons- } \\
\text { titucional (mayoría } \\
\text { simple) }\end{array}$ \\
\hline
\end{tabular}

Fuente: Elaboración propia.

constituyente que debe ser activada para una reforma total. La Tabla 3 recoge las características principales de estos tres mecanismos. En particular, analizaremos el procedimiento de la enmienda, mecanismo utilizado por el entonces presidente Rafael Correa para introducir la reelección indefinida.

Conforme con el artículo 441 de la Constitución ecuatoriana, un tercio de asambleístas pueden proponer una enmienda constitucional que no altere la estructura, carácter o elementos constitutivos del Estado y que no establezca restricciones a derechos y garantías, ni modifique el procedimiento de reforma constitucional. Luego, de acuerdo con el mismo artículo, se procede al primer debate, debiendo pasar un año y treinta días para que se realice el segundo debate en el Parlamento. La aproba- 
ción de la enmienda requiere dos terceras partes de los miembros de la Asamblea Nacional para su aprobación. ${ }^{42}$ Si se compara con la reforma parcial, la enmienda tramitada por vía legislativa es la vía menos gravosa para modificar el texto de la constitución.

La Constitución ecuatoriana exige que la Corte Constitucional califique la vía a través de la cual debe tramitarse una propuesta de reforma. Como adelantamos, la Corte Constitucional no dudó en legitimar el procedimiento más flexible de cambio constitucional: la enmienda por vía legislativa. ${ }^{43}$ La tesis central de la Corte, replicando la posición del ejecutivo, fue que la reelección indefinida no restringía, sino que ampliaba derechos constitucionales en tanto admitía que los electores eligieran libremente, sin limitaciones, y permitía a quien ejercía un cargo de elección popular volver a presentarse como candidato sin restricción temporal alguna.

El ejercicio altamente discrecional del poder de la Corte Constitucional para determinar la vía de reforma volvió a conveniencia más flexible el trámite de enmienda de la propia Constitución. La jurisprudencia constitucional emitida hasta el momento, por ejemplo, no había determinado con claridad el alcance de conceptos que limitan las disposiciones constitucionales susceptibles de enmienda constitucional según el artículo 441 de la Constitución, como la "estructura fundamental de la Constitución" o los "elementos constitutivos del Estado". De hecho, en el propio dictamen No. 1-14-DRC-CC, que declaró la procedencia de modificar los límites a la reelección presidencial vía enmienda, la Corte sostuvo dos criterios distintos sobre qué entender por elementos constitutivos del Estado. Por una parte, la magistratura expresó que los elementos constitutivos del Estado se encuentran recogidos únicamente en los artículos 1 a 9 de la Constitución y, por otra, que existen elementos constitutivos que pueden ser deducidos mediante interpretaciones de otras disposiciones constitucionales, ajenas a los artículos citados. Con estas argumentaciones

42 En contraste, según el artículo 442 de la Constitución, si la reforma no supone restricción de derechos y garantías constitucionales, ni modifique el procedimiento de reforma constitucional, pero altera la estructura fundamental o el carácter o elementos constitutivos del Estado, debe ser tramitada primero en la Asamblea y luego sometida a referéndum.

43 Dictamen 001-14-DRC-CC, dictado dentro del caso No. 0001-14-RC (2014). 
vacilantes, la Corte consideró que la eliminación de límites a la reelección no alteraba la estructura de la Constitución ni los elementos constitutivos del Estado.

Ello fue criticado por quienes sostenían que dicha interpretación modificaba la forma republicana del gobierno consagrada en el artículo 1 de la Constitución y anulaba el principio de alternancia democrática, según el cual las autoridades electas ejercen mandatos temporalmente acotados. Por ello, algunos expresaron que la introducción de la reelección indefinida podía realizarse mediante el procedimiento de reforma parcial (artículo 442 de la Constitución), mientras que otros estimaron que un cambio de tales magnitudes no solo que distorsionaba el sistema republicano, sino que potencialmente limitaba la democracia constitucional, restringía derechos constitucionales y, en consecuencia, requería de una asamblea constituyente. ${ }^{44}$ Estas interpretaciones eran políticamente inconvenientes para los intereses gubernamentales, en tanto requerían de un referéndum constitucional.

Ante la incertidumbre electoral, la crisis económica y el desgaste de su popularidad, Correa introdujo una disposición transitoria para aplicar la reelección indefinida de forma diferida por una sola vez. Esto significaba que Correa podía reelegirse sin limitaciones a partir de las elecciones generales de 2021.

En 2017, a punto de finalizar su gobierno luego de más de diez años, Correa apoyó la candidatura de su delfín, Lenín Moreno. Durante el primer año de gobierno, Moreno, convertido en el principal adversario político de Correa, convocó a una consulta popular para reformar la reelección indefinida y volver al esquema de la reelección inmediata. La propuesta fue aprobada en las urnas en febrero de 2018, desechando la reelección indefinida y retornando al esquema de reelección consecutiva.

En 2019, la nueva conformación de la Corte Constitucional revirtió la

44 Al respecto ver Benavides (2017), Benavides (2015), Bernal-Pulido, Caicedo y Serrafero (2015), CASTRo (2020). Además, ver: Carlos Bernal-Pulido, “Aún hay jueces en Berlín”, 23 de mayo de 2020. Diario El Universo. Disponible en: https://www.eluniverso.com/opinion/2014/09/03/ nota/3674921/aun-hay-jueces-berlin. 
interpretación en torno a la reelección indefinida, indicó que no existe un derecho a la reelección, que la eliminación de los límites a la misma no amplía derechos de participación y que más bien estas limitaciones son regulaciones legítimas que coadyuvan a la alternancia democrática de las autoridades electas en sus cargos. La Corte además resaltó que la reelección indefinida podría distorsionar el sistema democrático, volviéndolo incompatible con la democracia presidencial republicana. ${ }^{45}$

\section{La reelección presidencial indefinida en Bolivia (2017)}

Evo Morales Ayma, líder sindicalista cocalero, comenzó su actividad política a partir de 1980. En 1997, con el apoyo del Movimiento al Socialismo (MAS), fue elegido como diputado por el Departamento de Cochabamba. Participó en las elecciones presidenciales de 2002, en donde obtuvo la segunda votación más alta con el $20,94 \%$ de los votos. Luego de la denominada "guerra del gas", en 2003, Morales se posicionó como el principal candidato para ocupar la Presidencia de la República. En las elecciones de 2005 , Morales obtuvo el $54 \%$ de los votos, ganando por el más amplio margen que cualquier otro presidente durante el último periodo democrático de Bolivia. En marzo de 2006, Evo Morales logró la convocatoria a una asamblea constituyente. La nueva Constitución estableció la posibilidad de reelección inmediata, cambiando el esquema de reelección diferida vigente desde 1967.

En 2009 , Morales fue reelegido con el $64,22 \%$ de los votos. Si bien la nueva Constitución establecía que los mandatos anteriores al 2009 serían contabilizados a efectos del cómputo de nuevas reelecciones, maniobras interpretativas originadas en el legislativo y legitimadas por el Tribunal Plurinacional Constitucional permitieron a Morales postular a un tercer mandato consecutivo. En 2014, Morales resultó electo presidente con el $61,36 \%$ de la votación. Entre 2015 y 2016, Morales impulsó una reforma constitucional reeleccionista que le permitiese postular por cuarta vez a la presidencia. Esta propuesta, no obstante, fue rechazada vía

45 Dictamen No. 7-19-RC/19 (2019). 
referéndum. Ante la negativa popular, el poder político de Morales influyó para que, en el 28 de noviembre de 2017, el Tribunal Constitucional dicte una muy cuestionada sentencia en la que se declaró la inaplicabilidad de las limitaciones constitucionales a la reelección, argumentando la aplicación preferente de la Convención Americana de Derechos Humanos.

A finales de 2018, Morales inscribió su candidatura presidencial ante el Tribunal Supremo Electoral. En octubre de 2019 se celebraron las polémicas elecciones generales en las que Morales consiguió el 47,08\% de los votos. Denuncias de fraude electoral y el informe preliminar por parte de la Organización de Estados Americanos que ponía en duda la integridad de los comicios provocaron la radicalización de las movilizaciones ciudadanas y la escalada de la violencia social que menguó una vez que los militares retiraron su apoyo al gobierno. Menos de un mes más tarde de celebrados los comicios, Morales renunció a la presidencia. Hoy se debate la posibilidad de una candidatura de Morales al Senado boliviano.

\subsection{Poderes constitucionales del presidente}

Si se compara la Constituciones bolivianas de 1967 y de 2009, el desarrollo de las potestades legislativas y no legislativas del presidente es muy similar. En cuanto a las capacidades legislativas, los cambios más relevantes tienen que ver con la mayoría requerida para rechazar el veto -reducida por la Constitución de 2009 de dos tercios a mayoría absoluta de los miembros presentes en el legislativo- y la introducción de la facultad exclusiva del presidente para presentar proyectos de ley de urgencia económica que recibirán trato prioritario en el legislativo.

En lo referente a las capacidades no legislativas, la Constitución de 2009, a diferencia de su antecesora, no requiere del dictamen favorable de los ministros para la declaratoria de estados de excepción. Asimismo, la Constitución de 2009 le otorga al presidente la facultad de convocar a un referendo que dé paso a la reforma total de la constitución mediante una asamblea constituyente.

En materia de nombramiento y designación de funcionarios, tanto la Constitución de 1967 como la Constitución de 2009 facultan al presidente 
para designar, de una lista propuesta por el legislativo, al Contralor General del Estado, al Presidente del Banco Central, a la máxima autoridad del Órgano de Regulación de Bancos y Entidades Financieras y a los Presidentes de entidades de función económica y social en las cuales interviene el Estado.

Vale destacar que, conforme a la Constitución, el primer mandatario no tiene atribuciones de designación directa o mediante ternas de los jueces de las altas cortes, los cuales en Bolivia se designan mediante sufragio universal. Sin embargo, el sostenido predominio electoral del Presidente Morales y el apoyo de su bloque legislativo en la Asamblea, le ha permitido controlar tanto el proceso de precalificación de los candidatos a jueces, incluyendo los del Tribunal Constitucional, como incidir significativamente sobre la elección misma. La mayoría legislativa también fue clave para la designación de seis de los jueces del Tribunal Supremo Electoral, para cuya designación se requieren dos tercios de los votos de los legisladores presentes. El presidente solo designa directamente a uno de los siete miembros del Tribunal.

Si bien la Constitución de 2009 expandió significativamente las facultades legislativas y no legislativas del presidente, la nueva Carta Magna sí extendió de manera importante los periodos de mandato de cuatro años, sin posibilidad de reelección inmediata, a cinco años con la posibilidad de reelección consecutiva. Formalmente, este cambio significa que el presidente puede permanecer en el cargo por un lapso de diez años, en caso de lograr la reelección. Ya en la realidad, Morales logró permanecer en la presidencia desde 2005 hasta la actualidad, a través de interpretaciones legislativas validadas por los magistrados constitucionales.

En síntesis, las atribuciones legislativas y no legislativas del presidente pueden ser algo más limitadas en comparación a Ecuador, Venezuela o Nicaragua. Sin embargo, la ampliación del mandato con posibilidad de reelección, sumada a la mayoría legislativa ha permitido al mandatario impulsar reformas constitucionales, así como incidir en las candidaturas e incluso elección de los jueces de las altas cortes. Estos organismos, como analizaremos, han sido claves en la introducción de la reelección indefinida en Bolivia. 


\subsection{Independencia judicial y flexibilidad constitucional}

Conceptualmente, la Constitución boliviana podría considerarse como rígida debido a la exigencia del articulo 411 párrafo 2 de que "cualquier reforma parcial necesitará referendo constitucional aprobatorio”. En esa misma línea según el párrafo 1 del mismo artículo, toda reforma total o que afecte a las bases fundamentales de la Constitución, a los derechos, deberes y garantías o a la primacía y reforma de la Constitución requerirá Asamblea Constituyente activada mediante referendo.

En definitiva, toda reforma constitucional, parcial o total, requiere referendo. Sin embargo, el ejecutivo y el Tribunal Constitucional Plurinacional (TCP) encontraron formas alternativas de reformar el número de reelecciones posibles, mediante una serie de interpretaciones. ${ }^{46}$ Según el artículo 168 de la Constitución, el Presidente de la República puede ser reelecto por una sola vez de forma continua. Esto es lo que sucedió en el caso de Evo Morales, quien fue electo por primera vez en el 2005, antes de expedirse la nueva Constitución, y reelecto en el 2009. En consecuencia, Morales no podía optar por un tercer período pues la Constitución en la disposición transitoria primera, inciso II, establecía expresamente: "Ios mandatos anteriores a la vigencia de esta Constitución serán tomados en cuenta a los efectos del cómputo de los nuevos períodos de funciones". ${ }^{47}$

A pesar de la claridad de la disposición constitucional, el TCP habilitó a Evo Morales para un tercer período en 2013. Para el efecto, la Asamblea Nacional emitió la Ley 082 el 22 de febrero de 2013, a través de la cual los períodos de mandato debían contarse desde el 2009, es decir, desde la promulgación de la nueva Constitución. Efectivamente, la Ley 082 contradecía lo establecido en la transitoria de la Constitución. Posteriormente, el 25 de abril de 2013 el TCP avaló dicha la Ley 082, mediante cuestionables argumentos de refundación del Estado, declarándola

46 Sergio Verdugo, "How the Bolivian Constitutional Court Helped the Morales Regime to Break the Political Insurance of the Bolivian Constitution". Disponible en: http://www.iconnectblog. com/2017/12/how-the-bolivian-constitutional-court-helped-the-morales-regime-to-break-the-political-insurance-of-the-bolivian-constitution/.

47 Constitución Política del Estado, disposición transitoria primera, inciso II. 
constitucional, y viabilizando así la candidatura de Evo Morales para el 2014. ${ }^{48}$ Materialmente, la decisión del Tribunal permitió postular a una segunda reelección en la que Morales obtuvo el 61 por ciento de los votos.

EI TCP también fue clave para viabilizar el referendo convocado en 2015 que perseguía flexibilizar una vez más la reelección presidencial. ${ }^{49}$ Ello implicó que Evo Morales podría presentarse por una cuarta vez como candidato a una elección presidencial. Sin embargo, en este referéndum realizado en febrero de 2016, el gobierno de Morales sufrió una derrota electoral al perder por un margen de dos puntos porcentuales, lo que aparentemente significó el bloqueo de cualquier posibilidad de reelección para el mandatario. ${ }^{50}$

En septiembre de 2017, un grupo de senadores y diputados del Movimiento al Socialismo (MAS), el partido de Morales, presentaron una acción de inconstitucionalidad abstracta ante el TCP pidiendo que se declararan inaplicables los artículos constitucionales que limitan la reelección a una sola vez, por contravenir el artículo 23 de la Convención Americana de Derechos Humanos. Haciéndose eco de la argumentación de los accionantes, el TCP declaró la aplicación preferente de la Convención sobre las normas constitucionales, permitiendo así la reelección indefinida de Evo Morales en Bolivia. ${ }^{51}$

Según la interpretación del TCP, el artículo 23 numeral 2 de la Convención Americana desarrolla una enumeración taxativa de las condiciones por las cuales puede limitarse el derecho a elegir y ser elegido. ${ }^{52}$ Entre estas condiciones no se incluye el hecho de haber ejercido anteriormente la misma función pública a la que alguien se postula. En consecuencia, el

48 TCP Declaración Constitucional Plurinacional N 0003/2013.

49 TCP Declaración Constitucional Plurinacional Nº 0194/2015.

50 Nicholas Casey, "Evo Morales: ¿Un villano o líder histórico? Los bolivianos debaten su posible reelección", The New York Times, 29 de enero de 2018. Disponible en: https://www.nytimes. com/es/2018/01/29/evo-morales-reeleccion/.

51 Tribunal Constitucional Plurinacional, Sentencia Constitucional Plurinacional N ${ }^{\circ}$ 0084/2017.

52 El artículo 23 numeral 2 de la Convención señala: "2. La ley puede reglamentar el ejercicio de los derechos y oportunidades a que se refiere el inciso anterior, exclusivamente por razones de edad, nacionalidad, residencia, idioma, instrucción, capacidad civil o mental, o condena, por juez competente, en proceso penal". 
Tribunal señaló que la prohibición de reelección constituye una limitación de la Constitución al derecho a elegir y ser elegido contraria a la Convención Americana. De acuerdo con el artículo 256 de la Constitución boliviana, "los tratados e instrumentos internacionales en materia de derechos humanos que hayan sido firmados, ratificados o a los que se hubiere adherido el Estado, que declaren derechos más favorables a los contenidos en la Constitución, se aplicarán de manera preferente sobre ésta" ${ }^{53}$ En esta línea, el Tribunal decidió la aplicación preferente de la Convención y la inaplicabilidad de las limitaciones constitucionales a la reelección. ${ }^{54}$

Esta interpretación no solo tuvo como efecto la reelección de Morales, sino que paradójicamente también fue una de las causas de su caída. El afán reeleccionista de Evo y el MAS en un país tradicionalmente anti-reeleccionista, sumado a las maniobras para hacerse elegir, crearon el ambiente propicio para la ruptura democrática y marcaron el fin del régimen de Morales.

\section{La reelección presidencial indefinida en clave comparada}

La reelección indefinida fue instaurada a través de tres mecanismos: las enmiendas o reformas constitucionales aprobadas mediante consulta popular en el caso de Venezuela en 2009; las enmiendas o reformas constitucionales aprobadas por el legislativo en el caso de Nicaragua en 2014 y Ecuador en 2015 y las sentencias interpretativas de las altas cortes en los casos de Nicaragua en 2009 y Bolivia en 2017.

En los casos de Venezuela en 2009, Nicaragua en 2014 y Ecuador en 2015 la adopción de la reelección indefinida se produjo como consecuencia de un proceso de centralización de poder político en la figura del presidente de poderes en el presidente. Este proceso de fortalecimiento del ejecutivo tuvo como contracara el debilitamiento de la división de poderes y la ausencia de controles horizontales a las políticas del presidente. En efecto, la reelección presidencial indefinida se adoptó en contextos marcados por una subordinación institucional de los poderes

53 Constitución Política del Estado, artículo 256.

54 TCP, Sentencia Constitucional Plurinacional Nº084/2017. 
tradicionales frente a los intereses del ejecutivo.

La falta de independencia de las altas cortes frente al ejecutivo, precisamente fruto de la relación asimétrica entre el ejecutivo y las demás funciones estatales, evidencia uno de los más graves problemas institucionales en todos los casos analizados. Las cortes, en lugar de regular el poder político dentro de los límites establecidos por la constitución, han sido funcionales a los intereses presidenciales, declarando como inconstitucionales e inaplicables normas expresas de las propias constituciones. En Nicaragua y Bolivia, por ejemplo, cortes muy identificadas con los intereses del ejecutivo eliminaron los límites constitucionales a la reelección presidencial a través de sentencias interpretativas. Estos casos en los que la adopción de la reelección se produjo a través de la vía jurisprudencial muestran que los presidentes que no cuentan con el apoyo legislativo y popularidad suficiente para efectuar una reforma a la constitución por la vía legislativa o mediante referéndum, pero controlan una Corte que tiene el poder de realizar control de constitucionalidad también pueden aspirar a remover las prohibiciones a la reelección. El control político de una corte, sin embargo, puede estar directamente relacionado con la fortaleza del presidente en el legislativo, como en el caso boliviano.

Al igual que en Nicaragua y Bolivia, en Ecuador y Venezuela, las cortes reiteradamente viabilizaron la flexibilización de la reelección presidencial mediante sus fallos. A pesar de que la reelección no se decidió de manera definitiva en la arena judicial la dependencia política de las cortes determinó la suerte de las reformas reeleccionistas. En Venezuela, la Corte desestimó dos acciones que buscaban obstaculizar la enmienda propuesta por Chávez en 2009. En Ecuador, la Corte determinó la constitucionalidad para que el trámite de enmienda sea aprobado por en el legislativo, sin necesidad de someter la propuesta de reforma a consulta popular. Esta evidencia sugiere que las cortes politizadas, ya sea de manera directa o indirecta, han jugado un rol de legitimación de las reformas reeleccionistas propuestas por el presidente.

Si bien las constituciones de estos cuatro países han adoptado procedimientos de reforma constitucional agravados - que en ciertos casos re- 
quieren mayorías legislativas calificadas o ratificación mediante referéndum-, la rigidez y supremacía constitucional pueden verse seriamente debilitadas en contextos de presidentes fuertes, sumados a una justicia constitucional con escaza independencia frente al poder ejecutivo.

\section{Conclusiones}

Para la mayoría de corrientes del constitucionalismo, el éxito suele traducirse en la estabilidad y el respeto de los actores a las reglas constitucionales. Este no ha sido el caso de la reelección en América Latina. Las reglas de reelección presidencial en la región han sido altamente volátiles. Su reforma se ha producido en contextos de oleadas o tendencias reeleccionistas y anti reeleccionistas. La última oleada tuvo lugar desde 1990 hasta 2017 y reformó abrumadoramente el panorama de la reelección.

¿Cuáles fueron los factores que contribuyeron a la instauración de la reelección indefinida en Venezuela, Nicaragua, Ecuador y Bolivia durante la última década? En primer lugar, la reelección indefinida fue adoptada en contextos de presidentes fuertes, es decir, con amplias facultades constitucionales. Este hecho sugiere que la reelección indefinida es en realidad la punta del iceberg de un proceso más profundo que expresa una drástica concentración de poder en manos del presidente.

En segundo lugar, la instauración de la reelección presidencial indefinida se inscribe en un marco más amplio que refleja una crisis institucional muy marcada por el deterioro de la independencia judicial. Esta crisis institucional además está marcada por constituciones maleables en función de los intereses del presidente de turno. La mayoría de estos presidentes superaron con relativa facilidad los obstáculos formales para la tramitación y aprobación de enmiendas o reformas a la constitución. Cuando ello no fue posible, las cortes constitucionales fungieron como apoyos clave para viabilizar o establecer la reelección indefinida a través de sus decisiones. En Nicaragua y Bolivia, las altas cortes identificadas con los intereses del ejecutivo eliminaron los límites constitucionales a la reelección presidencial a través de sentencias que declararon la inapli- 
cabilidad de disposiciones expresas de la constitución. En Venezuela y Ecuador, las cortes habilitaron y legitimaron las propuestas reeleccionistas del presidente.

\section{Bibliografía}

AlbeRDI, Juan Bautista (1964). Bases y puntos de partida para la organización política de la República Argentina (Buenos Aires, Biblioteca Cervantes Virtual).

Aristóteles (2015). La Política: Aristoteles (Madrid, FV Éditions).

Barletta Villarán, Roberto (2011). Breve historia de Simón Bolívar (Madrid, Ediciones Nowtilus).

BENAVIDES, Jorge (2017). "La reelección presidencial indefinida en Ecuador. Una lectura crítica del dictamen de la Corte Constitucional que la permite vía enmienda constitucional" en Memoria, XII Congreso Iberoamericano de Derecho Constitucional, El diseño institucional del Estado democrático (Bogotá, Universidad del Externado).

BENAVIDES, Jorge (2015). Reforma constitucional, límites y deliberación democrática en Ecuador. Revista general de derecho público comparado, (17), 7.

Bernal-Pulido, Carlos. "Aún hay jueces en Berlín", 23 de mayo de 2020. Diario El Universo. Disponible en: https://www.eluniverso.com/ opinion/2014/09/03/nota/3674921/aun-hay-jueces-berlin.

Bernal-pulido, Carlos, Caicedo, Aparicio y Serrafero, Mario (2015): Reelección indefinida vs. Democracia constitucional: Sobre los límites al poder de reforma constitucional en el Ecuador (Bogotá, Universidad del Externado de Colombia).

BRENES, Amelia (2010): Jueces con curul: la reelección presidencial decidida en la vía jurisdiccional. Los casos de Costa Rica y Nicaragua, Tesis para la obtención del título de Máster en Estudios Latinoamericanos de la Universidad de Salam

BreWer-Carías, Allan R. (2009): "El Juez Constitucional vs. La alternabilidad republicana (La reelección continua e indefinida)", Revista de Derecho Público. 2009, vol. 117: pp. 205-211. 
Brewer-Carías, Allan R. (2009a). "Venezuela 2009 Referendum on Continuous Reelection: Constitutional Implications". Paper para el Panel "Venezuela Referendum: Public Opinion, Economic Impact and Constitutional Implications". Disponible en: https://core.ac.uk/download/ pdf/161436924.pdf. Fecha de consulta: 19 de abril de 2019.

CAREY, John M (2003): "The Reelection Debate in Latin America", en Latin American Politics and Society, vol. 45: pp. 119-133.

CASEY, Nicholas. "Evo Morales: ¿Un villano o líder histórico? Los bolivianos debaten su posible reelección" en The New York Times, 29 de enero de 2018, sec. América Latina. https://www.nytimes.com/ es/2018/01/29/evo-morales-reeleccion/.

CAstro, Cristina (2020). Rigidez de la constitución y reforma constitucional: estudio analítico de la actuación de los jueces constitucionales durante el período 2008-2019. Tesis de grado. Universidad Internacional SEK. Disponible en: https://repositorio.uisek.edu.ec/bitstream/123456789/3734/1/CRISTINA\%20CASTRO\%20MONTERO. pdf.

Castro-Montero, José Luis y van DiJck, Gijs (2017): “Judicial Politics in Unconsolidated Democracies: An Empirical Analysis of the Ecuadorian Constitutional Court (2008-2016)", en Justice System Journal, vol. 38, No 4: pp. 380-398.

Castro-Montero, Jose Luis y Proaño, Marco: "Argumentación como determinante de las decisiones judiciales: Evidencia empírica del control abstracto de constitucionalidad en Ecuador", en Revista Derecho del Estado, vol. 41: pp. 37-65.

Cheibub, Jose Antonio (2007). Presidentialism, Parliamentarism, and Democracy (New York, Cambridge University Press).

Colomer, Josep H. (2003). Political Institutions: Democracy and Social Choice (Oxford: Oxford University Press).

Coppedge, Michael (1998). "Venezuela: democrática a pesar del presidencialismo", en Las crisis del presidencialismo, vol. 2, pp. 335-370. Corrales, Javier y Penfold, Michael (2014): "Manipulating Term Limits in Latin America", Journal of Democracy, vol. 25: pp. 157-168.

Dixon, Rosalind y LANDAU, David (2020): "Constitutional End Games: Ma- 
king Presidential Term Limits Stick", Hastings Law Journal, vol. 71, p. 359.

Ginsburg, Tom (2012). Comparative Constitutional Design (New York, Cambridge University Press).

Ginsburg, Tom, Melton, James y Elkins, Zachary: "On the Evasion of Executive Term Limits”, Wm. \& Mary L. Rev., vol. 52: pp. 1807-1872.

Grijalva, Agustín, Guerra, Elsa y Martínez, Dunia (2016). "Constitutional limits on the power of the executive" en Gonzalez-Bertomeu, Juan F. y Gargarella, Roberto. The Latin American Casebook: Courts, Constitutions, and Rights (Routledge).

Hamilton, Alexander (2006): El federalista (México, Fondo de Cultura Económica).

HUME, David (1789). The History of England From The Invasion Of Julius Caesar To The Revolution in 1688, vol. 5 (JJ Tourneisen).

LEVITSKY, Steven (2018): "Democratic Survival and Weakness", Journal of Democracy, vol. 29, pp. 102-113.

LIJPHART, Arend (1990). "Presidencialismo y democracia de mayoría", en Hacia una democracia moderna: la opción parlamentaria, 1990, pp. 109-128.

Linz, Juan J. y Valenzuela, Arturo (1994). The Failure of Presidential Democracy (JHU Press).

Mainwaring, Scott y Pérez-Liñán, Aníbal (2015): "La democracia a la deriva en América Latina”, en Postdata, vol. 20, pp. 267-294.

MaINWARING, Scott, y Scully, Timothy R. (2008). "Latin America: Eight Lessons for Governance", en Journal of Democracy 19, no 3, pp. 113-27. Mainwaring, Scott, y Shugart Matthew Soberg (1997). Presidentialism and Democracy in Latin America (Cambridge, Cambridge University Press).

Maltz, Gideon (2007). "The Case for Presidential Term Limits”, en Journal of Democracy, vol. 18, pp. 128-142.

Martínez-Barahona, Elena y Brenes, Amelia (2012): "Cortes Supremas y candidaturas presidenciales en Centroamérica", Revista de Estudios Políticos, vol. 158: pp. 165-206.

Martínez-Barahona, Elena y Brenes, Amelia (2012): ““Y volver, volver, vol- 
ver..." Un análisis de los casos de intervención de las Cortes Supremas en la reelección presidencial en Centroamérica", Anuario de Estudios Centroamericanos, vol. 38: pp. 109-136.

Martínez-Barahona, Elena (2010) "Las Cortes Supremas como mecanismo de distribución de poder: el caso de la reelección presidencial en Costa Rica y Nicaragua", Revista Chilena de Ciencia Política, vol. 30, No 3: pp. 723-750.

País, Ediciones El. "Chávez reabre el proceso para su reelección indefinida”. El País. 1 de diciembre de 2008, sec. Internacional. https://elpais. com/diario/2008/12/01/internacional/1228086005_850215.html.

Petracca, Mark P (1996). "A History of Rotation in Office”, en Legislative Term Limits: Public Choice Perspectives, pp. 247-277.

“¿Por qué tiene que haber límites a la reelección?" Accedido 16 de julio de 2018. https://www.lanacion.com. ar/1438389-por-que-tiene-que-haber-limites-a-la-reeleccion.

PrImera, Maye. "Luz verde a la reforma constitucional para la reelección indefinida de Chávez". El País. 15 de enero de 2009, sec. Internacional. https://elpais.com/internacional/2009/01/15/actualidad/1231974005_850215.html.

SARTORI, Giovanni (1996). Ingenieria Constitucional Comparada (México, Fondo de Cultura Economica).

SeRrAfERo, Mario (2011). "La reelección presidencial indefinida en América Latina", en Revista de Instituciones, Ideas y Mercados, vol. 54, pp. 225-259.

Serrafero, Mario (1999): "Reelección y sucesión presidencial. Poder y Continuidad en Argentina, América Latina y EEUU”, en América latina hoy: Revista de ciencias sociales, vol. 17, pp. 106-155.

Shugart, Matthew Soberg y CAReY, John M (1992). Presidents and Assemblies: Constitutional Design and Electoral Dynamics (New York, Cambridge University Press).

SteIn, Charles W. (1943). The Third-term Tradition: Its rise and Collapse in American Politics (New York, Columbia University Press).

VARGAs Lima, Alan E. "La reelección presidencial en la jurisprudencia del Tribunal Constitucional Plurinacional de Bolivia.”, 2015. 
Verdugo, Sergio. "How the Bolivian Constitutional Court Helped the Morales Regime to Break the Political Insurance of the Bolivian Constitution". Accedido 21 de abril de 2019. http://www.iconnectblog. com/2017/12/how-the-bolivian-constitutional-court-helped-the-morales-regime-to-break-the-political-insurance-of-the-bolivian-constitution/.

Versteeg, Mila, Horley, Timothy, Meng, Anne, Guim, Mauricio y Guirguis, Marilyn. "The Law and Politics of Presidential Term Limit Evasion". SSRN Scholarly Paper. Rochester, NY: Social Science Research Network, 25 de marzo de 2019. https://papers.ssrn.com/abstract=3359960.

\section{Normas citadas}

Constitución de la República Bolivariana de Venezuela, 20 de diciembre de 2009.

Constitución de la República del ECuador, 20 de octubre de 2009.

Constitución Política del Estado de Bolivia, 7 de febrero de 2009.

Constitución Política de Nicaragua, publicada en La Gaceta No. 05 del 09 de enero de 1987, actualizada con las reformas de 1990, 1995, 2000, 2004, 2005 y 2014.

TRATADOS INTERNACIONALES

Convención Interamericana de Derechos Humanos, Costa Rica, (22 de noviembre de 1969).

\section{Jurisprudencia citada}

Sentencias de la Corte Interamericana de Derechos Humanos

Caso Castañeda Gutman vs. México. Corte Interamericana de Derechos Humanos. Sentencia de excepciones preliminares, fondo, reparaciones y costas, de 28 de agosto de 2013. Serie C No. 184.

Caso Yatama vs. Nicaragua. Corte Interamericana de Derechos Humanos. Sentencia de excepciones preliminares, fondo, reparaciones y costas, de 23 de junio de 2005. Serie C No. 127. 
SENTENCIAS DE LAS CORTES Y TRIBUNALES CONSTITUCIONALES NACIONALES

Corte Constitucional del Ecuador, Dictamen 001-14-DRC-CC emitido dentro del caso 0001-14-RC, publicado en el Registro Oficial No. 9 de 10 de noviembre de 2014.

Corte Constitucional del Ecuador, Dictamen 7-19-RC/19 de 5 de noviembre de 2019.

Sentencia No. 504-2009, de la Sala Constitucional de la Corte Suprema de Justicia de Nicaragua, dictada el 19 de octubre de 2009.

Sentencia No. 0053/2009, caso: Interpretación respecto del contenido y alcance de los artículos 340, 6 y 345 de la Constitución de la República Bolivariana de Venezuela, Sala de lo Constitucional del Tribunal Supremo de Justicia de Venezuela.

Tribunal Constitucional Plurinacional de Bolivia, Declaración Constitucional Plurinacional $N^{\circ}$ 0003/2013.

Tribunal Constitucional Plurinacional de Bolivia, Declaración Constitucional Plurinacional $N^{\circ}$ 0194/2015.

Tribunal Constitucional Plurinacional de Bolivia, Sentencia Constitucional Plurinacional $\mathrm{N}^{\circ}$ 0084/2017.

\section{OTROS}

CDL-AD (2018) 010-e, Reporte sobre límites al mandato presidencial, Comisión de Venecia, adoptado en la Sesión plenaria 114, Venecia, 17 de marzo de 2018. Disponible en: http://www.venice.coe.int/webforms/ documents/default.aspx?pdf=CDL-AD(2018)010-e\&lang=RU. Fecha de consulta: 19 de abril de 2019.

DiARIo El Comercio. Correa defiende reelección indefinida en Ecuador y desafía a opositores. Disponible en: https://www.elcomercio.com/actualidad/correa-defiende-reeleccion-constitucion-ecuador.html.

INFORME No. 30/93 de la Comisión Interamericana de Derechos Humanos, del caso 10.804 Guatemala el 12 de octubre de 1993. 
